\title{
Aortic surgery in pregnancy
}

Steven L. Lansman, MD, PhD, Joshua B. Goldberg, MD, Masashi Kai, MD, Gilbert H. L. Tang, MD, MSc, Ramin Malekan, MD, and David Spielvogel, MD

\begin{abstract}
Pregnancy engenders changes in hemodynamics and the aortic wall that make a woman more susceptible to aortic dilatation and dissection. This is particularly true of women with aortic dilatation and an aortopathy, including the inherited fibrillinopathies, bicuspid aortic valve, and Turner syndrome. Women in these risk groups may be served best by undergoing elective aortic surgery before becoming pregnant. However, some women present during pregnancy with significant aortic dilatation, rapid expansion, or aortic dissection, and strategies to deal with these situations, while optimizing maternal and fetal outcomes, change as gestation progresses. This review summarizes the approaches to the management of aortic diseases and the conduct of aortic surgery in pregnancy. (J Thorac Cardiovasc Surg 2017;153:S44-8)
\end{abstract}

Cardiac surgery rarely is performed during pregnancy. The Mayo Clinic database yielded only 21 such cases from 1976 to 2009, documenting 1 maternal death but significant fetal complications, including mortality $(14 \%)$, prematurity $(52 \%)$, intrauterine growth retardation $(5 \%)$, respiratory distress syndrome $(33 \%)$, and development delay $(14 \%){ }^{1}$ Surgery involving the thoracic aorta during pregnancy is even less common, constituting only 2 cases $(10 \%)$ in the Mayo series: 1 for a ruptured arch and 1 for rupture of the thoracoabdominal aorta.

From the Westchester Medical Center; and Department of Surgery, Section of Cardiothoracic Surgery, New York Medical College, Valhalla, NY.

Read at the 2016 Annual Aortic Symposium of the American Association of Thoracic Surgeons, New York, New York, May 12-13, 2016.

Received for publication April 15, 2016; revisions received May 5, 2016; accepted for publication June 11, 2016; available ahead of print July 16, 2016.

Address for reprints: Steven L. Lansman, MD, PhD, 100 Woods Rd, Macy Pavilion, 114W, Valhalla, NY 10595 (E-mail: Steven.Lansman@WMCHealth.org).

$0022-5223 / \$ 36.00$

Copyright (c) 2016 by The American Association for Thoracic Surgery

http://dx.doi.org/10.1016/j.jtcvs.2016.06.015

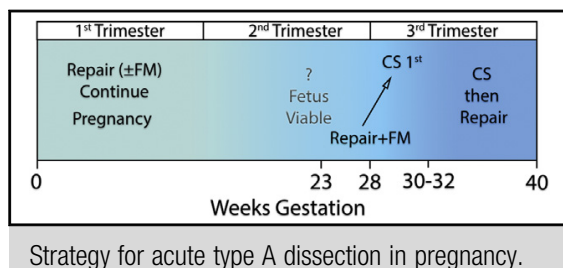

\section{Central Message}

Pregnant women with an aortopathy are more susceptible to AD. Management strategy changes as gestation progresses.

\begin{abstract}
Perspective
Pregnancy engenders hemodynamic and aortic wall changes that make women with aortic dilatation more susceptible to $\mathrm{AD}$, particularly those with an aortopathy. Although elective surgery before pregnancy is preferable, some women present during pregnancy with dilatation, rapid expansion, or acute dissection. This review summarizes management strategies, which change as gestation progresses.
\end{abstract}

See Editorial Commentary page S48.

\section{PHYSIOLOGY OF PREGNANCY}

Throughout gestation, progressive maternal hemodynamic and hematologic changes occur that affect aortic surgery. These include marked increases in heart rate, stroke volume, cardiac output, and left ventricular wall mass. ${ }^{2}$ However, a concurrent decrease in systemic vascular resistance serves to maintain a relatively stable blood pressure. By full term, plasma volume expands by approximately $40 \%$, but red cell mass increases by only $20 \%$, resulting in a dilutional decrease in hematocrit and viscosity. A procoagulant state also occurs, with increases in clotting factors and changes in fibrinolysis that perhaps anticipate the need for hemostasis at delivery. ${ }^{3}$

The hyperdynamic state of pregnancy affects the significance of obstructive lesions. For example, transvalvular

Scanning this QR code will take you to the article title page.

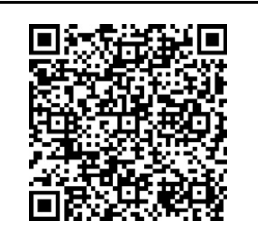




\section{Abbreviations and Acronyms \\ $\mathrm{AD}=$ aortic dissection \\ $\mathrm{BAV}=$ bicuspid aortic valve}

gradients across bicuspid aortic valves (BAVs) increase throughout pregnancy, peaking in the third trimester ${ }^{4}$; coarctation gradients increase, often causing refractory hypertension ${ }^{5}$; and even the gravid uterus can contribute to hypertension by causing aortoiliac compression. ${ }^{6}$

Particularly relevant to aortic surgery are pregnancyrelated changes in aortic dimensions and the structural integrity of the aortic wall. Normally, aortic diameter increases through pregnancy, most strikingly during the third trimester and postpartum period, and the effect is more dramatic in hypertensive and pre-eclamptic women. ${ }^{7}$ It has been hypothesized that circulating angiogenic factors required for the vascular development of the placenta and fetus may simultaneously mediate remodeling of the maternal vasculature, which helps to accommodate the hyperdynamic state of pregnancy. Although aortic dimensions revert toward baseline over the first 6 months postpartum, ${ }^{8}$ with ensuing pregnancies an enduring increase in aortic diameter occurs. ${ }^{9}$ Significantly, pregnancy also engenders a progressive, estrogen-mediated structural weakening of the aortic media caused by reticulin fragmentation and elastin fiber disorganization that peaks in the third trimester and postpartum period. ${ }^{10}$

\section{AORTIC DISSECTION IN PREGNANCY}

The hemodynamic and aortic wall changes of pregnancy predispose to aortic dissection (AD), with more than 50\% occurring in the third trimester and $33 \%$ occurring postpartum, ${ }^{6}$ when these changes are most pronounced. Although pregnancy is the most common risk factor for acute AD in young women, it is still a rare event. From 1998 to 2008, the Nationwide Inpatient Sample database logged 10,550,421 pregnancies and 41,000 acute ADs; only $44(0.1 \%)$ ADs occurred during pregnancy, representing $0.0004 \%$ of pregnancies. ${ }^{11}$ This comprises a yearly incidence of only 3.9 per 10,000, which is nonetheless 7-fold the yearly incidence of $\mathrm{AD}$ in the general population $(6 / 100,000) .{ }^{12} \mathrm{~A}$ recent literature review of aortic surgery in pregnancy found only 59 relevant articles, with 56 case reports and 3 series yielding 75 patients; $77 \%$ concerned type A dissection. ${ }^{13}$ Although rare, $\mathrm{AD}$ during pregnancy causes significant maternal and fetal mortality, as high as $30 \%$ and $50 \%$, respectively. ${ }^{14}$

\section{AORTOPATHY IN PREGNANCY}

Acute AD in young women most commonly occurs during pregnancy in women with a predisposing aortopathy, most commonly Marfan disease. Although the incidence of $\mathrm{AD}$ in pregnant women with Marfan disease is only $0 \%$ to $6.4 \%,{ }^{15}$ it is still tremendously higher than in women without Marfan disease, and a number of studies have sought to identify risk factors for $\mathrm{AD}$ in pregnant women with Marfan disease. As in much of aortic surgery, these risks generally are based on aortic size. In a study of 199 pregnancies in nulliparous women with Marfan disease, the aortic diameter expanded more rapidly than in non-Marfan controls, dilating by $3 \mathrm{~mm}$; postpartum the aortic diameter decreased, but not to baseline, and at more than 5 years of follow-up, women with Marfan had significantly larger aortic roots than nulliparous controls (43 vs $37 \mathrm{~mm}, P=.002$ ); multivariate analysis showed that only aortic size and rate of expansion predicted long-term adverse cardiovascular events. ${ }^{16}$ In asymptomatic patients with Marfan disease, aortic diameter, normalized by using the crosssectional area to height ratio, has been found to be a useful indicator for surgical intervention to prevent $\mathrm{AD},{ }^{17}$ and in pregnant women with fibrillinopathies, the risk of $\mathrm{AD}$ has been shown to increase as this ratio increases. ${ }^{18}$ The American College of Cardiology/American Heart Association Guidelines recommend that for women with Marfan disease who are contemplating pregnancy, it is reasonable to prophylactically replace the aortic root and ascending aorta if the diameter exceeds $4.0 \mathrm{~cm}$ (Table 1) $(4.5 \mathrm{~cm}$ by European guidelines ${ }^{19}$ ) and that surgical repair is reasonable if the cross-sectional area/height ratio exceeds $10 .^{20}$

Similar recommendations have been published for other fibrillinopathies, including vascular type Ehlers-Danlos $(\geq 4.5 \mathrm{~cm}),{ }^{15,19}$ Loeys-Dietz $\left(\geq 4.2 \mathrm{~cm}^{21} ; \geq 4.5 \mathrm{~cm}\right.$ by computed tomography ${ }^{20}$ ), and familial thoracic aneurysm and dissection $(\geq 4.5 \mathrm{~cm}),{ }^{22}$ as well as aortopathies, such as Turner syndrome $\left(\geq 27 \mathrm{~mm} / \mathrm{m}^{2}\right)^{23}$ and Turner syndrome with BAV $\left(\geq 25 \mathrm{~mm} / \mathrm{m}^{2}\right)$. ${ }^{24}$ These recommendations are summarized in Table 1. Inactive Takayasu arteritis has a low risk of causing a cardiovascular event during pregnancy and does not require intervention. ${ }^{25}$

$\mathrm{BAV}$ is thought to pose a risk for AD because of its association with ascending aortic dilatation, which is alternatively ascribed to hemodynamic forces, or an inherent aortopathy, and it has long been assumed that the hyperdynamic state of pregnancy accentuates that risk. Although pregnancy dramatically increases the gradient across a stenotic $\mathrm{BAV},{ }^{4}$ in a community-based study of 216 pregnancies in 88 women with $\mathrm{BAV}$, no $\mathrm{AD}$ occurred, and during 12.3 years of follow-up, these women did not have an increased risk of aortic dilatation, aortic surgery, or $\mathrm{AD} .{ }^{26}$ However, in general, it is recommended that aortic coarctation should be repaired before pregnancy, ${ }^{19}$ and an increased risk may exist when BAV is associated with coarctation, particularly in Turner syndrome. ${ }^{27,28}$

\section{PERIOPERATIVE MANAGEMENT}

Pregnant women with dilated thoracic aortas should undergo monthly or bimonthly echocardiographic measurement 
TABLE 1. Elective surgery for aortopathy in pregnancy

\begin{tabular}{|c|c|c|}
\hline Pathology & Elective surgery (mm) & $\begin{array}{c}\text { Cesarean } \\
\text { section }(\mathbf{m m})\end{array}$ \\
\hline \multicolumn{3}{|l|}{ Aortopathy } \\
\hline Marfan & $\geq 40^{20} ; \geq 45^{19 *}$ & $\geq 45^{19} \dagger$ \\
\hline Ehlers-Danlos IV & $\geq 45^{19 *}$ & $\mathrm{All}^{19}$ \\
\hline Loeys-Dietz & $\begin{array}{l}\geq 42^{21}(\mathrm{TEE})^{20} ; \\
\quad 44-46(\mathrm{CT} / \mathrm{MRI})^{20}\end{array}$ & $\geq 45^{19}$ \\
\hline FTAAD & $\geq 45$ & - \\
\hline Turner $( \pm \mathrm{BAV})$ & $\begin{array}{l}\geq 27 \quad\left(\mathrm{~mm} / \mathrm{m}^{2}\right)^{19} \\
\quad\left(\geq 25\left[\mathrm{~mm} / \mathrm{m}^{2}\right]^{24,28}\right)\end{array}$ & \\
\hline Bicuspid valve & $\geq 50^{24} \pm, \S$ & - \\
\hline \multicolumn{3}{|l|}{ Other } \\
\hline Aortic valve surgery & $\geq 45^{20}$ & - \\
\hline Aneurysm & $\geq 55^{20}$ & - \\
\hline Rapid growth ( $>5 \mathrm{~mm})$ & $\begin{array}{l}\text { Per y or during } \\
\text { pregnancy }\end{array}$ & - \\
\hline
\end{tabular}

$T E E$, Transesophageal echocardiography; $C T$, computed tomography; $M R I$, magnetic resonance imaging; $F T A A D$, familial thoracic aneurysm and dissection; $B A V$, bicuspid aortic valve. *Pregnancy contraindicated. Note: tissue frailty may make elective surgery higher risk. ${ }^{19} \dagger$ Consider at 40 to $45 \mathrm{~mm} .{ }^{19} \ddagger$ Considering pregnancy a risk for dissection. §Pregnancy contraindicated for aortic disease $\geq 50 \mathrm{~mm}$ associated with BAV. ${ }^{19}$

of the ascending aortic dimensions until delivery. ${ }^{20}$ If possible, elective surgery should be postponed until after delivery, but, as a general principle, necessary surgery should not be denied because of pregnancy and the surgery should be performed in a facility with capable obstetric and neonatal services, including the availability of fetal monitoring and $\mathrm{Ce}$ sarean section. ${ }^{19}$

\section{CARDIOPULMONARY BYPASS DURING PREGNANCY}

The fetoplacental unit depends on properly functioning maternal and fetal circulations. On the fetal side, cardiac output is rate dependent, so it is important to avoid fetal bradycardia. Also, oxygen delivery is precarious. The fetal "oxygenator," the placenta, drains into the fetal venous circulation so that fetal arterial blood is a venous admixture, with fetal hemoglobin approximately $65 \%$ saturated. The oxyhemoglobin dissociation curve is left shifted to improve oxygen uptake, but consequently oxygen delivery is decreased. On the maternal side, to maximize oxygen delivery, it is important to maintain maternal cardiac output, blood pressure, hemoglobin, and $\mathrm{pH}$. It is also critical to avoid uterine contractions, because they severely restrict uterine and placental blood flow and are a major cause of fetal death. Of note, hemodilution should be avoided on cardiopulmonary bypass, because it may decrease progesterone levels and induce contractions.

A number of caveats to observe in the conduct of cardiopulmonary bypass have been recommended. ${ }^{1,29}$ Experimental evidence supports the use of pulsatile perfusion, because it promotes nitric oxide-mediated placental vasodilation, ${ }^{30}$ but currently available equipment rarely support this mode. Strategies to augment maternal blood supply to the placenta include maintaining high flow, pressure, and hematocrit, whereas hypothermia, which may induce placental vasoconstriction, should be minimized. Likewise, vasoconstrictors should be avoided. So initially, hypotension should be treated by increasing pump flow, but if necessary, pressors that tend to have less splanchnic vasoconstriction, such as phenylephrine or vasopressin, should be used sparingly. ${ }^{1}$ If arch surgery is necessary, moderate hypothermia might be used, using selective antegrade cerebral perfusion, and distal perfusion should be maintained. Retrograde cerebral perfusion probably should be avoided, particularly if the inferior vena cava is snared, because elevated venous pressure may adversely affect the precarious placental perfusion gradient.

Although hypothermia is to be avoided, a recent literature survey included 5 cases in whom deep hypothermic circulatory arrest was used. Fetal $(40 \%)$ and maternal $(20 \%)$ mortality were high, but not $100 \%{ }^{13}$

\section{TIMING OF AORTIC SURGERY IN PREGNANCY}

The following overview of timing for aortic surgery in pregnancy should be qualified by noting that many of the recommendations are based on case series and a synthesis of current published opinion. There are few issued guidelines, and even these emphasize the want of evidence in this area.

For women seeking counseling before becoming pregnant, the European guidelines advise that pregnancy "should be discouraged" in patients with Marfan disease with aortic root dilatation $4.5 \mathrm{~cm}$ or greater, and, although recently called into question, ${ }^{31}$ pregnancy is contraindicated in Ehlers-Danlos syndrome. It is recommended that women in various risk groups who have aortic dilatation exceeding recommended size thresholds (Table 1) undergo elective surgery before pregnancy. During pregnancy, however, if significant aortic dilatation is discovered or rapid aortic expansion $(\geq 5 \mathrm{~mm})$ occurs, particularly in a member 
of a high-risk group, a number of options need to be weighed in regard to the timing of surgery. Early in pregnancy, maternal risk may warrant termination of pregnancy. During the first trimester, surgery carries a significant risk of causing fetal developmental anomalies, whereas during the third trimester, significant risks of maternal and fetal circulatory collapse are incurred. The safest period to undertake semielective surgery is during the second trimester, because fetal organogenesis is largely completed, but maternal hemodynamic changes are not yet fully established. ${ }^{27,32}$

Emergency surgery, such as repair of acute type A AD, should be undertaken regardless of trimester. During the first trimester and much of the second trimester, if continuation of pregnancy is desired, obstetric consultation is warranted. Fetal monitoring may provide useful feedback for managing cardiopulmonary bypass, but nonetheless fetal loss is common (Figure 1). During the late second and early third trimesters, strategy depends on fetal viability, which in turn may depend on the experience of the local neonatal service. Currently, the prospects for independent fetal survival is very poor at less than 23 weeks gestation, but becomes increasingly likely over subsequent weeks. During this period, strategy involves balancing at least 3 risks: (1) the risk of fetal loss, if pregnancy is continued; (2) the risks of neonatal prematurity, if Cesarean section is performed; and (3) the risk of maternal mortality. Uterine smooth muscle contraction compressing the spiral arteries is a major component of hemostasis after delivery. In concert, however, anesthesia, smooth muscle relaxation, hypothermia, and obligatory full anticoagulation may pose a risk for fatal hemorrhage should Cesarean section be undertaken during cardiopulmonary bypass. Thus, if Cesarean section is part of the operative strategy, it should be undertaken before anticoagulation and cardiopulmonary bypass. With the increasing likelihood of independent fetal survival, particularly after 32 weeks gestation, Cesarean section followed by aortic repair offers the best chance for fetal and maternal survival.

Type B AD should be managed medically unless complicated by malperfusion, which should be managed by an endovascular approach if possible. Of note, the European Guidelines do not consider a previous type B dissection to be a contraindication to pregnancy. ${ }^{19}$

\section{CONCLUSIONS}

Maternal accommodations for pregnancy include the development of a hyperdynamic state and aortic wall changes that, although benefiting fetal development, increase the risk of $\mathrm{AD}$, particularly for women with predisposing aortopathies. These factors must be considered in the perioperative management of pregnant patients and in the conduct of cardiopulmonary bypass. Appropriate surgical strategy involves choosing not only the best procedure but also the optimum timing for surgery. Although aortic

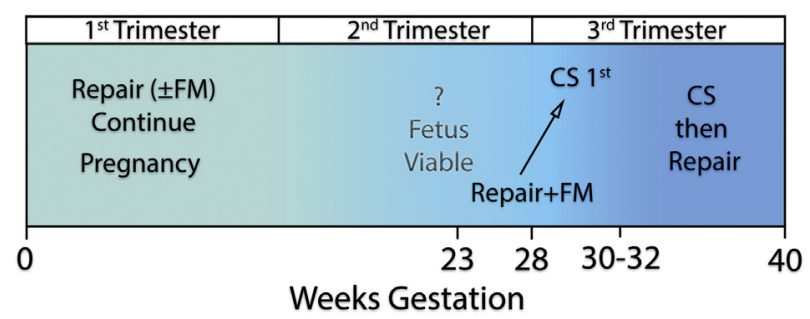

FIGURE 1. Strategy for acute type A dissection in pregnancy. FM, Fetal monitoring; $C S$, Cesarean section.

surgery rarely is required during pregnancy, an understanding of the progressive developmental and hemodynamic circumstances that occur throughout gestation is crucial to achieving the best fetal and maternal outcomes.

\section{Conflict of Interest Statement}

Authors have nothing to disclose with regard to commercial support.

\section{References}

1. John AS, Gurley F, Schaff HV, Warnes CA, Phillips SD, Arendt KW, et al. Cardiopulmonary bypass during pregnancy. Ann Thorac Surg. 2011;91:1191-6.

2. Smok DA. Aortopathy in pregnancy. Semin Perinatol. 2014;38:295-303.

3. Patel A, Asopa S, Tang AT, Ohri SK. Cardiac surgery during pregnancy. Tex Heart Inst J. 2008;35:307-12.

4. Yuan SM. Bicuspid aortic valve in pregnancy. Taiwan J Obstet Gynecol. 2014 53:476-80.

5. Beauchesne LM, Connolly HM, Ammash NM, Warnes CA. Coarctation of the aorta: outcome of pregnancy. J Am Coll Cardiol. 2001;38:1728-33.

6. Crawford JD, Hsieh CM, Schenning RC, Slater MS, Landry GJ, Moneta GL, et al Genetics, pregnancy, and aortic degeneration. Ann Vasc Surg. 2016;30:e155-9.

7. Easterling TR, Benedetti TJ, Schmucker BC, Carlson K, Millard SP. Maternal hemodynamics and aortic diameter in normal and hypertensive pregnancies. $\mathrm{Ob}$ stet Gynecol. 1991;78:1073-7.

8. Hart MV, Morton MJ, Hosenpud JD, Metcalfe J. Aortic function during norma human pregnancy. Am J Obstet Gynecol. 1986;154:887-91.

9. Gutin LS, Merz AE, Bakalov VK, Gharib AM, Bondy CA. Parity and aortic dimensions in healthy women. Int J Cardiol. 2013;165:383-4.

10. Manalo-Estrella P, Barker AE. Histopathologic findings in human aortic media associated with pregnancy. Arch Pathol. 1967;83:336-41.

11. Sawlani N, Shroff A, Vidovich MI. Aortic dissection and mortality associated with pregnancy in the United States. J Am Coll Cardiol. 2015;65:1600-1.

12. Howard DP, Banerjee A, Fairhead JF, Perkins J, Silver LE, Rothwell PM, Oxford Vascular Study. Population-based study of incidence and outcome of acute aortic dissection and premorbid risk factor control: 10-year results from the Oxford Vascular Study. Circulation. 2013;127:2031-7.

13. Rajagopalan S, Nwazota N, Chandrasekhar S. Outcomes in pregnant women with acute aortic dissections: a review of the literature from 2003 to 2013. Int J Obstet Anesth. 2014;23:348-56.

14. Immer FF, Bansi AG, Immer-Bansi AS, McDougall J, Zehr KJ, Schaff HV, et al. Aortic dissection in pregnancy: analysis of risk factors and outcome. Ann Thorac Surg. 2003;76:309-14.

15. van Hagen IM, Roos-Hesselink JW. Aorta pathology and pregnancy. Best Pract Res Clin Obstet Gynaecol. 2014;28:537-50.

16. Donnelly RT, Pinto NM, Kocolas I, Yetman AT. The immediate and long-term impact of pregnancy on aortic growth rate and mortality in women with Marfan syndrome. J Am Coll Cardiol. 2012;60:224-9.

17. Svensson LG, Khitin L. Aortic cross-sectional area/height ratio timing of aortic surgery in asymptomatic patients with Marfan syndrome. J Thorac Cardiovasc Surg. 2002;123:360-1.

18. Bradley EA, Zaidi AN, Goldsmith P, Sisk T, Colombo D, Roble S, et al. Major adverse maternal cardiovascular-related events in those with aortopathies What should we expect? Int J Cardiol. 2014;177:229-34.

19. European Society of Gynecology (ESG); Association for European Paediatric Cardiology (AEPC); German Society for Gender Medicine (DGesGM)Regitz- 
Zagrosek V, Blomstrom Lundqvist C, Borghi C, Cifkova R, Ferreira R, Foidart JM, et al. ESC Guidelines on the management of cardiovascular diseases during pregnancy: the Task Force on the Management of Cardiovascular Diseases during Pregnancy of the European Society of Cardiology (ESC). Eur Heart J. 2011;32:3147-97.

20. Hiratzka LF, Bakris GL, Beckman JA, Bersin RM, Carr VF, Casey DE Jr, et al. 2010 ACCF/AHA/AATS/ACR/ASA/SCA/SCAI/SIR/STS/SVM Guidelines for the Diagnosis and Management of Patients With Thoracic Aortic Disease: A Report of the American College of Cardiology Foundation/American Heart Association Task Force on Practice Guidelines, American Association for Thoracic Surgery, American College of Radiology, American Stroke Association, Society of Cardiovascular Anesthesiologists, Society for Cardiovascular Angiography and Interventions, Society of Interventional Radiology, Society of Thoracic Surgeons, and Society for Vascular Medicine. Circulation. 2010;121:e266-369.

21. Svensson LG, Adams DH, Bonow RO, Kouchoukos NT, Miller DC, O'Gara PT, et al. Aortic valve and ascending aorta guidelines for management and quality measures: executive summary. Ann Thorac Surg. 2013;95:1491-505.

22. Wanga S, Silversides C, Dore A, de Waard V, Mulder B. Pregnancy and thoracic aortic disease: managing the risks. Can J Cardiol. 2016;32:78-85.

23. Matura LA, Ho VB, Rosing DR, Bondy CA. Aortic dilatation and dissection in turner syndrome. Circulation. 2007;116:1663-70.

24. Hiratzka LF, Creager MA, Isselbacher EM, Svensson LG, Nishimura RA, Bonow RO, et al. Surgery for aortic dilatation in patients with bicuspid aortic valves: a statement of clarification from the American College of Cardiology/ American Heart Association Task Force on Clinical Practice Guidelines. J Am Coll Cardiol. 2016;67:724-31

25. Tanaka H, Tanaka K, Kamiya C, Iwanaga N, Yoshimatsu J. Analysis of pregnancies in women with Takayasu arteritis: complication of Takayasu arteritis involving obstetric or cardiovascular events. J Obstet Gynaecol Res. 2014;40: 2031-6.

26. McKellar SH, MacDonald RJ, Michelena HI, Connolly HM, Sundt TM III. Frequency of cardiovascular events in women with a congenitally bicuspid aortic valve in a single community and effect of pregnancy on events. Am J Cardiol. 2011;107:96-9.

27. Yates MT, Soppa G, Smelt J, Fletcher N, van Besouw JP, Thilaganathan B, et al Perioperative management and outcomes of aortic surgery during pregnancy J Thorac Cardiovasc Surg. 2015;149:607-10.

28. Carlson M, Airhart N, Lopez L, Silberbach M. Moderate aortic enlargement and bicuspid aortic valve are associated with aortic dissection in Turner syndrome: report of the international turner syndrome aortic dissection registry. Circulation. 2012;126:2220-6.

29. Chandrasekhar S, Cook CR, Collard CD. Cardiac surgery in the parturient. Anesth Analg. 2009;108:777-85.

30. Vedrinne C, Tronc F, Martinot S, Robin J, Allevard AM, Vincent M, et al. Better preservation of endothelial function and decreased activation of the fetal reninangiotensin pathway with the use of pulsatile flow during experimental fetal bypass. J Thorac Cardiovasc Surg. 2000;120:770-7.

31. Murray ML, Pepin M, Peterson S, Byers PH. Pregnancy-related deaths and complications in women with vascular Ehlers-Danlos syndrome. Genet Med. 2014; $16: 874-80$

32. Balsam LB, DeAnda A Jr. Double the jeopardy: balancing maternal and fetal risk during cardiac surgery. J Thorac Cardiovasc Surg. 2015;149:611-2.

Key Words: aorta, aortopathy, pregnancy, dissection, aneurysm

\title{
EDITORIAL COMMENTARY
}

\section{In pregnancy, aortic tissue is the issue}

\author{
Ourania Preventza, MD, and Joseph S. Coselli, MD
}

\footnotetext{
From the Division of Cardiothoracic Surgery, Baylor College of Medicine; and the Division of Cardiovascular Surgery, Texas Heart Institute, Houston, Tex.

Disclosures: O.P. is a consultant for Medtronic and WL Gore \& Associates. J.S.C. participates in clinical research trials conducted by Glaxo Smith Kline, Edwards Lifesciences, and Bolton Medical; consults for, receives royalties and a departmental educational grant from, and participates in clinical trials for Vascutek Terumo; consults and participates in clinical trials for Medtronic, Inc; and consults and participates in clinical trials for WL Gore \& Associates.

Received for publication June 27, 2016; accepted for publication June 27, 2016; available ahead of print July 26, 2016.

Address for reprints: Ourania Preventza, MD, BCM 390, One Baylor Plaza, Houston, TX 77030 (E-mail: opsmile01@aol.com).

J Thorac Cardiovasc Surg 2017;153:S48-9

$0022-5223 / \$ 36.00$

Copyright $(2016$ by The American Association for Thoracic Surgery

http://dx.doi.org/10.1016/j.jtcvs.2016.06.050
}

In this elegant report, Lansman and colleagues ${ }^{1}$ provide an interesting review of a complex topic: Management of aortic disease and aortic dissection in pregnancy. The available literature offers little evidence concerning this

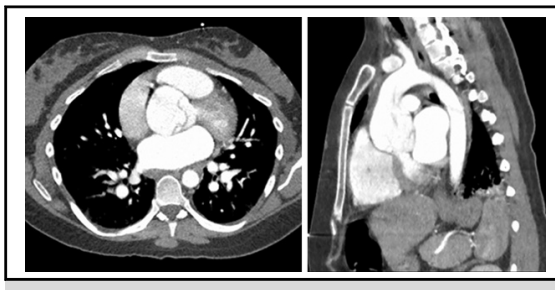

CT images of a type A dissection that occurred 1 week postpartum in a patient with Marfan syndrome.

\section{Central Message}

topic, so this reA multidisciplinary team can optimize management and determine whether pregnancy is inadview should be applauded. The visable or aortic repair needed before pregnancy.

See Article page S44. authors concisely describe the hyperdynamic state and aortic wall changes that occur during 